\title{
Efeito da aplicação foliar de silício na resistência à ferrugem e na potencialização da atividade de enzimas de defesa em cafeeiro
}

\author{
Sandra C. Pereira ${ }^{1}$, Fabrício A. Rodrigues ${ }^{2}$, Vivian Carré-Missio ${ }^{2}$, Maria Goreti A. Oliveira ${ }^{1} \&$ Laércio \\ Zambolim ${ }^{2}$
}

${ }^{1}$ Departamento de Bioquímica Agrícola; ${ }^{2}$ Departamento de Fitopatologia, Universidade Federal de Viçosa, 36570-000, Viçosa, MG, Brasil

Autor para correspondência: Fabrício A. Rodrigues, e-mail: fabricio@ufv.br

\section{RESUMO}

A principal medida de controle da ferrugem do cafeeiro, causada por Hemileia vastatrix, é o uso de fungicidas. O fornecimento de silício ( $\mathrm{Si}$ ) às plantas é uma estratégia de controle interessante considerando o potencial desse elemento em aumentar a resistência de várias espécies de plantas à patógenos. Este trabalho avaliou o efeito da aplicação foliar do Si na redução da severidade da ferrugem e na possível potencialização da atividade de seis enzimas relacionadas com a resistência de plantas à patógenos. Mudas de café (cultivar Catuaí Vermelho 44) foram pulverizadas com água destilada, solução de silicato de potássio (KSi) (35 g/L, pH 10,5), KSi (35 g/L, pH 5,5) e solução de acibenzolar-S-metil (ASM) $(200 \mu \mathrm{g} / \mathrm{L}) 24$ horas antes da inoculação. Não houve diferença significativa entre os tratamentos para os teores foliares de Si e potássio. A severidade foi significativamente maior em mudas pulverizadas com água em relação aos demais tratamentos. O ASM reduziu significativamente a severidade em $70 \%$ em relação à aplicação de água. A aplicação de soluções de KSi, independente do $\mathrm{pH}$, também reduziu a severidade. O ASM foi eficiente em aumentar a atividade de quitinases e $\beta$-1,3-glucanases, porém a aplicação de KSi, independente do $\mathrm{pH}$ da solução, foi ineficiente em potencializar a atividade das seis enzimas estudadas, embora tenha reduzido a severidade.

Palavras-chave: Hemileia vastatrix, mecanismo bioquímico de defesa, nutrição mineral.

\begin{abstract}
Effect of foliar silicon application on resistance against coffee leaf rust and on the potentiation of defense enzymes in coffee

The major method for control of coffee leaf rust, caused by Hemileia vastatrix, is the use of fungicides. The supply of silicon (Si) to plants is an interesting control strategy because this element can increase the resistance of many plant species to pathogens. This study aimed to evaluate the effect of foliar application of $\mathrm{Si}$ on reducing rust severity as well as to determine if it can potentiate the activity of enzymes related to host resistance to pathogens. Coffee plants (cultivar Catuaí Vermelho 44) were sprayed with distilled water, potassium silicate (KSi) solution (35 g/L, pH 10.5), KSi (35 g/L, pH 5.5), and acibenzolar-S-methyl (ASM) solution (200 $\mu \mathrm{g} / \mathrm{L}) 24$ hours before inoculation. There was no significant difference among the treatments regarding the content of Si and potassium in the leaf tissue. Rust severity was significantly higher on plants sprayed with water as compared to the other treatments. The ASM significantly decreased rust severity by $70 \%$ in comparison to the water spray treatment. Foliar application of KSi, regardless of the $\mathrm{pH}$, was efficient in decreasing rust severity. The ASM was efficient in increasing the activity of chitinases and $\beta$-1,3-glucanases. On the other hand, the application of $\mathrm{KSi}$, regardless of the $\mathrm{pH}$, was inefficient to potentiate the activity of these six enzymes studied, even though it had a great impact on reducing rust severity.
\end{abstract}

Keywords: Hemileia vastatrix, biochemical mechanism of host defense, mineral nutrition.

\section{INTRODUÇÃO}

A ferrugem, causada pelo fungo Hemileia vastatrix Berk. \& Br., é a principal doença do cafeeiro no Brasil.

Parte da Dissertação de Mestrado da primeira autora. Universidade Federal de Viçosa. Viçosa MG. 2007.
Perdas na produção em até $30 \%$ já foram relatadas quando as condições climáticas foram favoráveis à ocorrência de epidemias severas da doença (Zambolim et al., 2002). O manejo da ferrugem envolve principalmente o uso de fungicidas protetores cúpricos, sistêmicos do grupo dos triazóis, isoladamente ou em mistura com as estrobirulinas, e o uso de cultivares resistentes (Zambolim et al., 2002). Entretanto, devido à grande variabilidade do patógeno, a tão almejada resistência durável tem sido difícil de ser obtida (Várzea \& Marques, 2005), associado ao fato de que 
o uso contínuo de fungicidas pode levar ao surgimento de populações resistentes.

A nutrição mineral é um dos fatores ambientais de fácil manipulação pelo homem visando o controle de doenças em plantas cultivadas. Embora não considerado essencial às plantas, porém benéfico, o silício $(\mathrm{Si})$ tem aumentado a resistência de várias espécies de plantas às pragas, doenças, bem como a diversos tipos de estresses abióticos tais como altas temperaturas, falta de água no solo e toxidez de ferro e manganês às raízes quando teores elevados desses elementos se acumulam nos tecidos dessas espécies, na sua maioria monocotiledôneas (Mitani \& Ma, 2005; Datnoff et al., 2007).

Os mecanismos pelos quais o $\mathrm{Si}$ atual na resistência das plantas à patógenos ainda não estão totalmente esclarecidos. A hipótese da formação de uma barreira física abaixo da cutícula após a polimerização do ácido monosilícico explica, em parte, o aumento da resistência do arroz a brusone (Datnoff et al., 2007). Tentativamente, essa hipótese vem sendo usada por vários pesquisadores como um dos argumentos para explicar a resistência de algumas espécies de plantas a certos patógenos quando supridas com Si. Contudo, o abundante acúmulo de compostos fenólicos associados com as estruturas de alguns patógenos nos sítios de infecção e o aumento na produção de algumas classes de fitoalexinas em arroz (Datnoff et al., 2007), a transcrição de alguns genes em arroz associados com a resistência à brusone (Rodrigues et al., 2005), e o incremento na atividade de enzimas líticas à parede celular fúngica ou associadas com o metabolismo secundário da planta (Liang et al., 2005) reforçam a hipótese de que o Si potencializa mecanismos de defesa em plantas e não atua apenas de forma passiva na resistência. Em cafeeiro, sabe-se que plantas crescendo em solo contendo Si foram mais resistentes à cercosporiose, resistência essa atribuída a deposição de Si na superfície foliar e uma camada de cera e cutícula mais espessas (Pozza et al., 2004). Em pepineiro, reconhecido como sendo uma planta intermediária na capacidade de acumular Si na parte aérea, a aplicação foliar em Si controlou o míldio pulverulento, mas não foi capaz de potencializar a atividade das enzimas peroxidases, polifenoloxidases e quitinases, ao contrário do que foi obtido em plantas supridas com $\mathrm{Si}$ via solo onde o controle da doença, além de ser efetivo, esteve associado com aumento na atividade dessas enzimas durante o processo infeccioso (Liang et al., 2005).

Não existem relatos na literatura sobre a capacidade do cafeeiro em absorver Si quando fontes desse elemento são aplicadas via foliar e caso seja eficientemente absorvido, se o mesmo passa a potencializar certas respostas de defesa da planta contra patógenos. Assim, o presente trabalho objetivou avaliar o efeito do Si aplicado via foliar na redução da severidade da ferrugem em cafeeiro, além da possível potencialização da atividade das enzimas quitinases, $\beta$-1,3glucanases, peroxidases, polifenoloxidases, lipoxigenases e fenilalanina amônia-liases, envolvidas nas respostas de defesa das plantas a patógenos.

\section{MATERIAL E MÉTODOS}

\author{
Silicato de potássio via foliar na redução da severidade \\ da ferrugem
}

$\mathrm{O}$ experimento foi instalado em delineamento inteiramente casualizado (DIC) com quatro tratamentos e oito repetições. Cada repetição foi constituída por um vaso contendo uma muda de café (cultivar Catuaí Vermelho 44) contendo três pares de folhas completamente abertos. As mudas de café foram obtidas do Viveiro de Café do Departamento de Fitopatologia da Universidade Federal de Viçosa. Os tratamentos utilizados nesse estudo foram mudas pulverizadas com: água destilada, solução de silicato de potássio (KSi) $(35 \mathrm{~g} / \mathrm{L}, \mathrm{pH} 10,5)\left(\right.$ Fertisil $^{\circledR}$, PQ Silicas Brasil Ltda), KSi (35 g/L, pH 5,5) e solução de acibenzolarS-metil (ASM) $(200 \mu \mathrm{g} / \mathrm{L}) 24$ horas antes da inoculação com $H$. vastatrix. $\mathrm{O} \mathrm{pH}$ da solução de KSi for reduzido de 10,5 para 5,5 utilizando-se ácido fosfórico $5 \mathrm{M}$. O tratamento com ASM foi incluído para fins comparativos com o KSi, já que o mesmo é considerado um indutor de defesa de plantas a patógenos, incluindo o patossistema cafeeiro-H. vastatrix (Guzzo et al., 2001).

Vinte quatro horas após a aplicação foliar dos produtos, realizou-se a inoculação da face abaxial do $2^{\circ} \mathrm{e}$ do $3^{\circ}$ par de folhas de cada muda com uma suspensão de uredósporos de $H$. vastatrix na concentração de $1 \mathrm{mg} / \mathrm{mL}$. O inóculo utilizado foi obtido de plantas de café (cultivar Catuaí vermelho 44) previamente inoculadas com uredósporos da raça II de $H$. vastatrix. Após a inoculação, as plantas foram transferidas para câmara úmida (UR $>95 \%, 23-25^{\circ} \mathrm{C}$ ) onde permaneceram no escuro por 48 horas. Posteriormente, as mudas foram transferidas para câmara de crescimento a $22^{\circ} \mathrm{C}$ até a finalização do experimento. Aos 36 dias após a inoculação, avaliouse a severidade da ferrugem utilizando a escala proposta por Kushalappa (1978) no $2^{\circ}$ e $3^{\circ}$ par de folhas, sendo considerada a média desses dois pares. Essa escala consiste de três diagramas de folhas de café com 30,50 e $70 \%$ de suas áreas marcadas para indicar a severidade da ferrugem, sendo que em cada folha uma conhecida quantidade de área com $1,3,5,7$ e $10 \%$ é ocupada por pústulas individuais ou por pústulas coalescidas.

\section{Determinação da concentração foliar de Si e potássio} (K)

As folhas das plantas inoculadas das repetições de cada um dos quatro tratamentos foram coletadas no final do experimento realizado para estudar o efeito do Si na redução da severidade da ferrugem, lavadas com água deionizada, secadas em estufa com ventilação forçada de ar a $60^{\circ} \mathrm{C}$ por 72 horas e trituradas em moinho tipo Wiley com peneira de 20 mesh. O teor foliar de Si foi determinado de acordo com a metodologia proposta por Korndörfer et al. (2004) e o de K por espectrometria de absorção atômica. 
Efeito da aplicação foliar de silício na resistência à ferrugem...

Silicato de potássio via foliar na potencialização da atividade de enzimas envolvidas com a resistência do cafeeiro à ferrugem

$\mathrm{O}$ experimento foi instalado em DIC com oito repetições. Mudas de cafeeiro foram pulverizadas com os produtos descritos anteriormente 24 horas antes de serem inoculadas com $H$. vastatrix. $\mathrm{O} 2^{\circ}$ e o $3^{\circ}$ par de folhas inoculadas de cada muda foram coletadas aos 1, 2, 4, 14 e 36 dias após a inoculação (DAI) com $H$. vastatrix. Folhas pulverizadas com água destilada e não inoculadas também foram coletadas nos mesmos períodos de tempo. Foram coletadas seis folhas das mudas inoculadas ou não com $H$. vastatrix para cada época de coleta. As amostras coletadas foram armazenadas individualmente em papel alumínio, rapidamente congeladas em nitrogênio $\left(\mathrm{N}_{2}\right)$ líquido e, em seguida, armazenadas a $-80^{\circ} \mathrm{C}$. Os ensaios enzimáticos foram realizados em triplicata para cada extrato foliar. Foram determinadas as atividades das seguintes enzimas:

Quitinases (QUI) (EC 3.2.1.14) e $\beta$-1,3-glucanases (GLU) (EC 3.2.1.39): amostras pesadas e congeladas em $\mathrm{N}_{2}$ líquido foram trituradas no almofariz com adição de polivinilpolipirrolidona (PVPP) $1 \%(\mathrm{p} / \mathrm{v})$. O pó obtido foi macerado em tampão fosfato de sódio $50 \mathrm{mM}, \mathrm{pH} 6,5$, contendo fluoreto de fenilmetilsulfonila (PMSF) $1 \mathrm{mM}$. A centrifugação foi feita a $20.000 \times g$ por 25 minutos a $4^{\circ} \mathrm{C}$. Uma alíquota do sobrenadante foi utilizada para determinação da concentração de proteínas (Silva et al., 2001).

A atividade de QUI foi determinada conforme método descrito por Harman et al. (1993) e Roberts \& Selitrennikoff (1988). A mistura de reação, incubada a $37^{\circ} \mathrm{C}$ por 2 horas, continha $470 \mu \mathrm{L}$ do tampão de reação

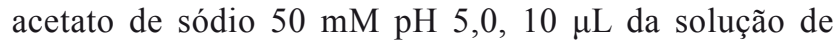
substrato $p$-nitrofenil- $\beta$-D- $N, N^{\prime}$-diacetilquitobiose 2 $\mathrm{mg} / \mathrm{mL}$ e $20 \mu \mathrm{L}$ do extrato vegetal. Após esse período, foram acrescentados $0,5 \mathrm{~mL}$ de carbonato de sódio 0,2 M. As amostras tiveram a absorbância registrada no comprimento de onda $410 \mathrm{~nm}$ em um ensaio colorimétrico no espectrofotômetro. Todas as incubações foram realizadas em triplicatas. Subtraiu-se o valor de absorbância de cada amostra do valor de absorbância do controle (uma mistura idêntica à da amostra, com a reação paralisada no início). Os resultados foram expressos em unidades de absorbância. $\mathrm{min}^{-1} / \mathrm{mg}$ de proteína.

A atividade de GLU foi determinada conforme método descrito por Lever (1972) com modificações, onde o ácido 3,5-dinitrosalicílico (DNS) foi substituído pela hidrazida do ácido $p$-hidroxibenzóico. A mistura de reação, incubada a $45^{\circ} \mathrm{C}$ por 30 minutos, continha $230 \mu \mathrm{L}$

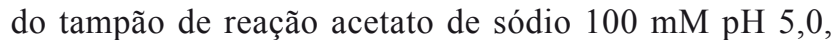
$250 \mu \mathrm{L}$ da solução de substrato laminarina $(4 \mathrm{mg} / \mathrm{mL})$ e $20 \mu \mathrm{L}$ do extrato vegetal. Após esse período, adicionouse $1 \mathrm{~mL}$ de DNS e, em seguida, a mistura foi aquecida a $100^{\circ} \mathrm{C}$ por 5 minutos. Após resfriamento em gelo até a temperatura de $30^{\circ} \mathrm{C}$, as amostras tiveram a absorbância registrada no comprimento de onda $540 \mathrm{~nm}$ em um ensaio colorimétrico no espectrofotômetro. Todas as incubações foram realizadas em triplicatas. Subtraiu-se o valor de absorbância de cada amostra do valor de absorbância do controle (uma mistura idêntica à da amostra, com a reação paralisada no início). Os resultados foram expressos em unidades de absorbância. $\mathrm{min}^{-1} / \mathrm{mg}$ de proteína.

Peroxidases(POX)(EC 1.11.1.7), polifenoloxidases(PFO) (EC 1.10.3.1) e lipoxigenases (LOX) (EC 1.13.11.12): amostras pesadas e congeladas $\mathrm{em} \mathrm{N}_{2}$ líquido foram trituradas no almofariz com adição de PVPP $1 \%(\mathrm{p} / \mathrm{v})$. O pó obtido foi macerado em tampão fosfato de potássio $100 \mathrm{mM}, \mathrm{pH} 6,8$, contendo PMSF $1 \mathrm{mM}$ e ácido etilenodiamino tetra-acético (EDTA) $0,1 \mathrm{mM}$. A centrifugação foi feita a $12.000 \mathrm{x} g$ por 15 minutos a $4^{\circ} \mathrm{C}$. Uma alíquota do sobrenadante foi utilizada para determinação da concentração de proteínas (Silva et al., 2001). A atividade de POX e PFO foi determinada conforme método descrito por Kar \& Mishra (1976). Para a atividade de POX, a mistura de reação que continha $950 \mu \mathrm{L}$ de água destilada, $750 \mu \mathrm{L}$ do tampão de reação fosfato de

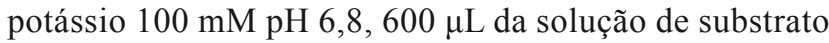
pirogalol $100 \mathrm{mM}$ e $600 \mu \mathrm{L}$ de peróxido de hidrogênio $100 \mathrm{mM}$ foi levada ao banho-maria à temperatura de $25^{\circ} \mathrm{C}$ para estabilização por aproximadamente 4 minutos. Para a atividade de $\mathrm{PFO}$, a mistura de reação que continha $1550 \mu \mathrm{L}$ de água destilada, $750 \mu \mathrm{L}$ do tampão de reação fosfato de potássio $100 \mathrm{mM} \mathrm{pH} 6,8$ e $600 \mu \mathrm{L}$ da solução de substrato pirogalol $100 \mathrm{mM}$ foi levada ao banho-maria à temperatura de $25^{\circ} \mathrm{C}$ para estabilização por aproximadamente 4 minutos. Ao meio de reação para cada uma dessas enzimas, foram adicionados 100 $\mu \mathrm{L}$ do extrato vegetal e o aumento na absorbância foi registrado no comprimento de onda $420 \mathrm{~nm}$ em um ensaio colorimétrico no espectrofotômetro durante um período de 5 minutos em intervalos de 1 minuto. Todas as incubações foram realizadas em triplicatas. Utilizouse para os cálculos o coeficiente de extinção molar 2,47 $\mathrm{mM}^{-1} \cdot \mathrm{cm}^{-1}$ (Chance \& Maehley, 1955) para as duas enzimas e os resultados foram expressos em M. $\mathrm{min}^{-1} / \mathrm{mg}$ de proteína.

A atividade de LOX foi determinada conforme método descrito por Axelrod et al. (1981). A mistura de reação contendo $2 \mathrm{~mL}$ do tampão de reação fosfato de sódio $50 \mathrm{mM}$ pH 6,0 e $30 \mu \mathrm{L}$ da solução de substrato linoleato de sódio $10 \mathrm{mM}$ foi levada ao banho-maria à temperatura de $25^{\circ} \mathrm{C}$ para estabilização por aproximadamente $4 \mathrm{~min}$. Durante a reação foram adicionados $30 \mu \mathrm{L}$ do extrato vegetal e, então, o aumento na absorbância foi registrado no comprimento de onda $234 \mathrm{~nm}$ em um ensaio colorimétrico no espectrofotômetro durante um período de 3 minutos em intervalos de 30 segundos. Todas as incubações foram realizadas em triplicatas. Utilizou-se para os cálculos o coeficiente de extinção molar $25.000 \mathrm{M}$ ${ }^{1} . \mathrm{cm}^{-1}$ (Axelrod et al., 1981) e os resultados foram expressos em M.min ${ }^{-1} / \mathrm{mg}$ de proteína. 
Fenilalanina amônia-liases (FAL) (EC 4.3.1.5): amostras pesadas e congeladas em $\mathrm{N}_{2}$ líquido foram trituradas no almofariz. O pó obtido foi macerado em tampão borato de sódio $0,1 \mathrm{M}, \mathrm{pH} 8,8$, contendo polivinilpirrolidona $5 \%(\mathrm{p} / \mathrm{v})$ e $\beta$-mercaptoetanol $20 \mathrm{mM}$. A centrifugação foi realizada a $12.000 \mathrm{x} g$ por 20 minutos a $4^{\circ} \mathrm{C}$. Uma alíquota do sobrenadante foi utilizada para determinação da concentração de proteínas (Silva et al., 2001). A atividade de FAL foi determinada conforme método descrito por Cahill \& Mccomb (1992). A mistura de reação que continha $1 \mathrm{~mL}$ do tampão de reação borato de sódio $0,2 \mathrm{M} \mathrm{pH} 8,8$ e $1 \mathrm{~mL}$ da solução do substrato $L$-fenilalanina $0,1 \mathrm{M}$ foi levada ao banho-maria à temperatura de $30^{\circ} \mathrm{C}$ para estabilização por aproximadamente 4 minutos. Durante a reação adicionou-se $1 \mathrm{~mL}$ do extrato vegetal e, então, o aumento na absorbância foi registrado no comprimento de onda $290 \mathrm{~nm}$ em um ensaio colorimétrico no espectrofotômetro durante um período de 5 minutos em intervalos de 1 minuto. Todas as incubações foram realizadas em triplicatas. Utilizou-se para os cálculos o coeficiente de extinção molar $10^{4} \mathrm{mM}^{-1} \cdot \mathrm{cm}^{-1}$ (Zucker, 1965). Os resultados foram expressos em M.min ${ }^{-1} / \mathrm{mg}$ de proteína.

\section{RESULTADOS E DISCUSSÃO}

Não houve diferença significativa entre os tratamentos quanto aos teores foliares de $\mathrm{Si}$ e de $\mathrm{K}$. Os teores foliares de $\mathrm{Si}$ e de K variaram, respectivamente, entre 0,45 a $0,51 \%$ e de 2,67 a $2,74 \%$. Sabe-se que as espécies de plantas diferem quanto à capacidade em absorver o Si do solo e translocá-lo, de forma eficiente, para a parte aérea (Mitani \& Ma, 2005). O arroz, a cana-de-açúcar e outras gramíneas, reconhecidas como acumuladoras de $\mathrm{Si}$, chegam a apresentar até $5 \%$ de Si na matéria seca da parte aérea (Datnoff et al., 2007). Contrariamente, o cafeeiro mostrou ser uma espécie ineficiente em absorver o $\mathrm{Si}$, contido no

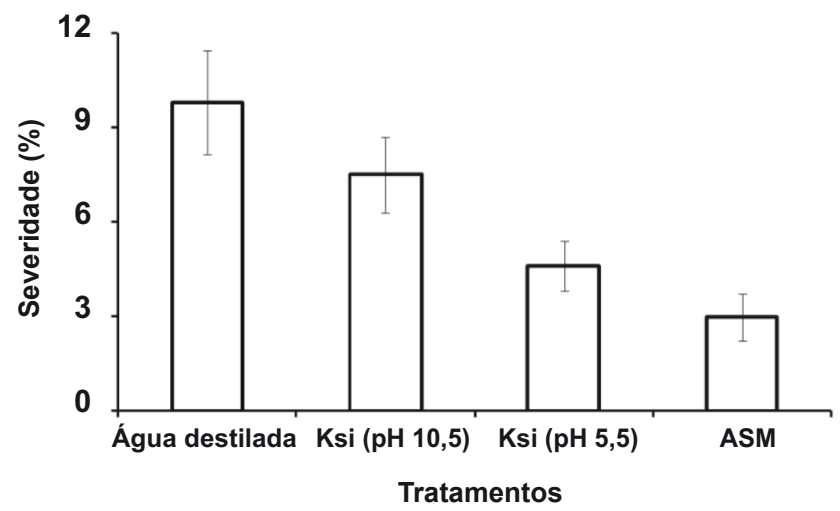

FIGURA 1 - Severidade da ferrugem aos 36 dias após a inoculação das mudas de cafeeiro com Hemileia vastatrix que receberam previamente a aplicação foliar de água destilada, silicato de potássio (KSi) (pH 10,5), KSi $(\mathrm{pH} \mathrm{5,5)} \mathrm{e} \mathrm{acibenzolar-S-metil}$ (ASM).
KSi aplicado via foliar, apresentando teores comparáveis aos de outras espécies de plantas reconhecidas como não acumuladoras de $\mathrm{Si}$, a exemplo do tomateiro (Mitani \& Ma, 2005). Quando fontes de Si como o silicato de cálcio e silicato de sódio foram adicionadas ao solo, os teores foliares desse elemento em mudas de cafeeiro foram de 0,44 e 0,65 $\mathrm{mg} \mathrm{kg}{ }^{-1}$, respectivamente (Botelho et al., 2005). Pode-se considerar que os valores encontrados por esses autores são extremamente baixos, mesmo fornecendo o Si via solo, com base no que se é conhecido para outras culturas (Mitani $\& \mathrm{Ma}, 2005)$. A eficiência do arroz em absorver ativamente o Si do solo deve-se a presença de proteínas transportadoras do Si localizadas nas estrias de Caspary da exoderme e da endoderme (Ma et al., 2007). Entretanto, em outras espécies de plantas, a exemplo de Coffea arabica, se desconhece até o momento a presença de genes responsáveis pela produção dessas proteínas carreadoras de Si no sistema radicular.

A severidade da ferrugem foi significativamente maior em mudas que receberam a aplicação de água em relação aos demais tratamentos (Figura 1). A aplicação do ASM reduziu significativamente a severidade em $70 \%$ em relação ao tratamento correspondente à aplicação de água. O ASM tem sido eficiente em ativar sistemicamente mecanismos de defesa em plantas que são efetivos a um grande número de patógenos fúngicos e bacterianos (Lyon, 2007). De acordo com Guzzo et al. (2001), plantas de café da cultivar Mundo Novo foram protegidas, local e sistemicamente, contra a ferrugem quando pulverizadas com diferentes concentrações do ASM, com redução expressiva na produção de uredósporos nas pústulas examinadas. A aplicação foliar de soluções de KSi com pH 10,5 e 5,5 também mostrou-se eficiente em reduzir a severidade, principalmente quando em $\mathrm{pH}$ mais ácido (Figura 1). Sabese que em $\mathrm{pH}$ mais alcalino, o KSi em solução é mais estável e não polimeriza rapidamente quando $\mathrm{em} \mathrm{pH}$ mais ácido, o que pode afetar, por um maior período de tempo, a germinação dos uredósporos de $H$. vastatrix na superfície foliar por possíveis alterações no potencial osmótico. O fornecimento de $\mathrm{Si}$ às plantas, seja via solo, solução nutritiva ou foliar, tem resultado num controle satisfatório de várias doenças, tanto em mono quanto em dicotiledôneas (Datnoff et al., 2007). Existem relatos de que no patossistema arrozPyricularia grisea e arroz-Rhizoctonia solani, plantas de diferentes cultivares supridas com Si apresentaram reduções significativas em vários componentes de resistência tais como a taxa de expansão de lesões, a freqüência de infecção e a área abaixo da curva do progresso da doença (Datnoff et al., 2007). Particularmente em cafeeiro, Pozza et al. (2004) relataram que mudas da cultivar Catuaí crescidas em substrato contendo silicato de cálcio apresentaram redução de $63,2 \%$ na porcentagem de folhas lesionadas e de $43 \%$ no total de lesões por planta, em relação às plantas que não foram supridas com Si. Observações no microscópio eletrônico de varredura acoplado a microanálise de raios- $\mathrm{X}$ indicaram que em folhas das plantas dessa cultivar supridas com $\mathrm{Si}$, esse elemento foi distribuído uniformemente em 
toda a superfície abaxial das folhas. Além disso, a cutícula foi mais espessa e a camada de cera epicuticular apresentouse mais desenvolvida na superfície abaxial das folhas de plantas supridas com $\mathrm{Si}$, o que tornou a superfície mais hidrofóbica impedindo, de certa forma, a formação de um filme de água importante para a germinação dos conídios de Cercospora coffeicola. Nas folhas das plantas não supridas com $\mathrm{Si}$, a deposição de $\mathrm{Si}$ raramente foi observada e não ocorreu nenhuma alteração perceptível na camada de cera. Botelho et al. (2005) também relataram controle da cercosporiose em mudas de café da cultivar Catuaí IAC99 crescidas em substrato contendo doses crescentes de silicato de cálcio e de silicato de sódio. Nesse estudo, os autores obtiveram os menores valores para a área abaixo da curva de progresso da doença e área abaixo da curva de progresso do número de plantas com cercosporiose, respectivamente, nas doses de 0,84 e 0,52 g de silicato de sódio por $\mathrm{kg}$ de substrato.

A atividade de QUI decresceu do $1^{\circ}$ para o $2^{\circ}$ DAI para todos os tratamentos, com exceção do ASM, a semelhança das plantas não inoculadas (Figura 2). Do $2^{\circ}$ para o $4^{\circ} \mathrm{DAI}$, houve decréscimo na atividade de QUI para todos os tratamentos, com exceção do KSi pH 10,5. Houve um pico na atividade de QUI aos 14 DAI para o ASM enquanto que para os demais tratamentos a atividade dessa enzima manteve-se num patamar similar ao observado para as plantas não inoculadas. Em comparação às plantas não inoculadas, houve aumento na atividade de QUI nas plantas pulverizadas com água e com KSi em pH 10,5 aos 36 DAI.

A atividade de GLU decresceu do $1^{\circ}$ para o $2^{\circ}$ DAI para todos os tratamentos, com exceção do ASM, a semelhança das plantas não inoculadas (Figura 3). Assim como para as plantas não inoculadas, a atividade de GLU aumentou do $2^{\circ}$ para o $4^{\circ}$ DAI para todos os tratamentos. Houve decréscimo na atividade de GLU do $4^{\circ}$ para o $14^{\circ}$ DAI para os tratamentos ASM e KSi pH 5,5 em relação às plantas não inoculadas, mas aumento em atividade para os tratamentos KSi pH 10,5 e pulverização com água. Dos 14 aos 36 DAI, houve aumento na atividade de GLU para os tratamentos ASM, KSi pH 5,5 e pulverização com água a semelhança das plantas não inoculadas, mas decréscimo para o tratamento KSi pH 10,5.

No $1^{\circ} \mathrm{DAI}$, a atividade de POX foi menor para todos os tratamentos em relação às plantas não inoculadas (Figura 4). Em comparação às plantas não inoculadas, a atividade de POX aumentou do $1^{\circ}$ para o $2^{\circ}$ DAI para todos os tratamentos, com exceção do ASM. No $4^{\circ} \mathrm{DAI}$, a atividade de POX manteve-se similar entre todos os tratamentos, mas aumentou aos 14 DAI para todos eles. Do $14^{\circ}$ ao $36^{\circ} \mathrm{DAI}$, a atividade de POX aumento para os tratamentos ASM e plantas pulverizadas com água, porém a atividade mantevese inferior em relação ao tratamento correspondente às plantas não inoculadas. Houve decréscimo na atividade de POX para os tratamentos KSi pH 10,5 e KSi pH 5,5.

A atividade de PFO foi menor para todos os tratamentos em relação às plantas não inoculadas no $1^{\circ}$ DAI, mas aumentou aos 2 DAI (Figura 5). A semelhança

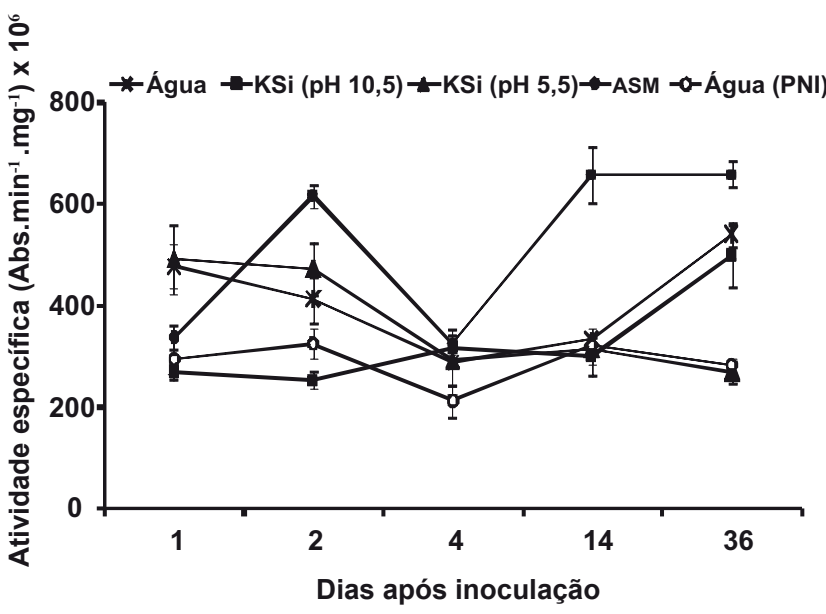

FIGURA 2 - Atividade específica de quitinases em folhas de mudas de cafeeiro determinada em diferentes épocas após a inoculação com Hemileia vastatrix e que receberam previamente a aplicação foliar de água destilada, silicato de potássio (KSi) (pH 10,5), KSi (pH 5,5) e acibenzolar-S-metil (ASM). Plantas não inoculadas (PNI) receberam aplicação de água destilada. Barras representam o desvio padrão da média.

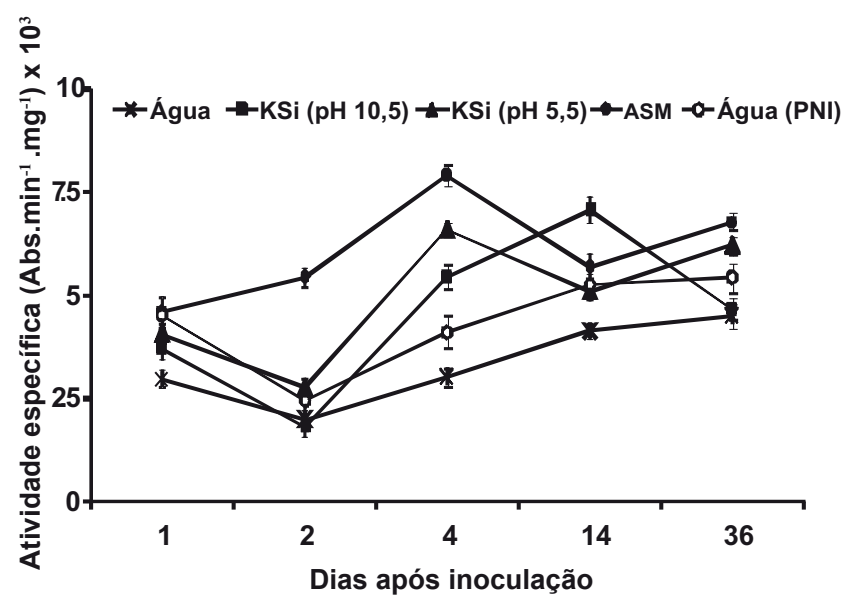

FIGURA 3 - Atividade específica de $\beta$-1,3-glucanases em folhas de mudas de cafeeiro determinada em diferentes épocas após a inoculação com Hemileia vastatrix e que receberam previamente a aplicação foliar de água destilada, silicato de potássio (KSi) (pH 10,5), KSi (pH 5,5) e acibenzolar-S-metil (ASM). Plantas não inoculadas (PNI) receberam aplicação de água destilada. Barras representam o desvio padrão da média.

das plantas não inoculadas, a atividade de PFO decresceu para todos os tratamentos do $2^{\circ}$ para o $4^{\circ} \mathrm{DAI}$, com exceção do ASM. Do $4^{\circ}$ para o $14^{\circ}$ DAI, a atividade de PFO aumentou para todos os tratamentos em relação as plantas não inoculadas, com exceção do ASM. A atividade de PFO aumentou do $14^{\circ}$ para o $36^{\circ}$ DAI para todos os tratamentos, com exceção do $\mathrm{KSi}$ pH 10,5, a semelhança do que foi observado para as plantas não inoculadas. 


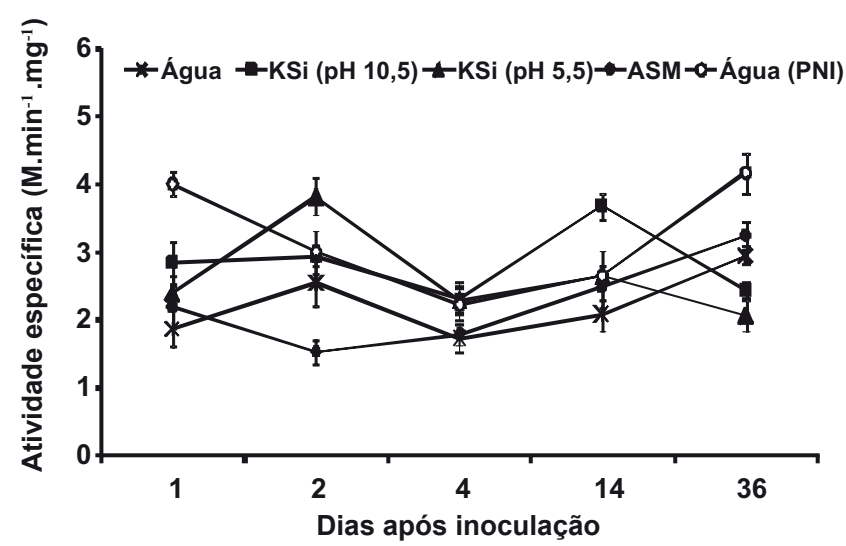

FIGURA 4 - Atividade específica de peroxidases em folhas de mudas de cafeeiro determinada em diferentes épocas após a inoculação com Hemileia vastatrix e que receberam previamente a aplicação foliar de água destilada, silicato de potássio (KSi) (pH 10,5), KSi (pH 5,5) e acibenzolar-S-metil (ASM). Plantas não inoculadas (PNI) receberam aplicação de água destilada. Barras representam o desvio padrão da média.

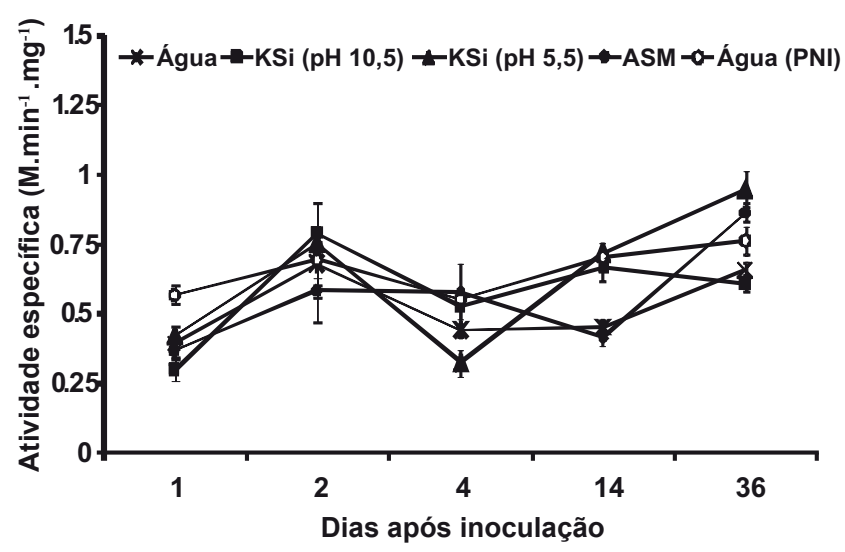

FIGURA 5 - Atividade específica de polifenoloxidases em folhas de mudas de cafeeiro determinada em diferentes épocas após a inoculação com Hemileia vastatrix e que receberam previamente a aplicação foliar de água destilada silicato de potássio (KSi) (pH 10,5), KSi (pH 5,5) e acibenzolar-S-metil (ASM). Plantas não inoculadas (PNI) receberam aplicação de água destilada. Barras representam o desvio padrão da média.

A atividade de LOX manteve-se superior para todos os tratamentos em relação às plantas não inoculadas do $1^{\circ}$ ao $14^{\circ}$ DAI (Figura 6). Assim como para as plantas não inoculadas, a atividade de LOX decresceu para todos os tratamentos do $1^{\circ}$ para o $4^{\circ} \mathrm{DAI}$, com exceção dos tratamentos KSi pH 5,5 e ASM. Houve aumento na atividade de LOX do $4^{\circ}$ ao $14^{\circ}$ DAI para todos os tratamentos mesmo para as plantas não inoculadas, com exceção do KSi pH 5,5. Do $14^{\circ}$ ao $36^{\circ} \mathrm{DAI}$, a atividade de LOX aumentou apenas para os tratamentos pulverização com água e ASM, assim como para as plantas não inoculadas.

A atividade de FAL manteve-se superior para todos os tratamentos em relação às plantas não inoculadas no $1^{\circ}$ DAI, mas decresceu aos 2 DAI (Figura 7). Aos 4 DAI, a atividade de FAL manteve-se similar entre os tratamentos incluindo as plantas não inoculadas, mas houve aumento aos 14 DAI. Aos 14 DAI, a atividade de FAL foi superior para todos os tratamentos com exceção para o KSi pH 5,5 em semelhança ao que foi observado para as plantas não inoculadas. Aos 36 DAI, a atividade de FAP continuou superior para os tratamentos ASM e plantas pulverizadas com água, aumentou para o KSi pH 5,5 e decresceu para o KSi pH 10,5 em relação às plantas não inoculadas.

As plantas são capazes de ativar rapidamente, mas de forma orquestrada, diferentes mecanismos bioquímicos de defesa associados com o metabolismo secundário após a infecção por patógenos. Sabe-se que as enzimas QUI e GLU são eficientes em degradar a parede celular dos fungos e contribuírem para gerar elicitores que ativam as respostas de defesa da planta (Okinaka et al., 1995). Durante o processo infeccioso por patógenos necrotróficos ou hemibiotróficos, os danos físicos por eles ocasionados a membrana plasmática celular causa a degradação dos lipídeos pela ação das lipoxigenases, gerando hidroperóxidos dos ácidos graxos correspondentes e a expressão da resistência de algumas plantas a patógenos (Silva et al., 2001). A rota dos fenilpropanóides, iniciada pela conversão da $L$-fenilalanina a ácido trans-cinâmico, numa reação de deaminação catalisada pela enzima FAL, é de suma importância para a produção de compostos fenólicos de natureza antimicrobiana, além de certas classes de fitoalexinas (Schuster \& Rétey, 1995). As POX estão relacionadas com o processo de proteção antioxidativa catalisando a oxidação de componentes celulares como o peróxido de hidrogênio e também no aumento da síntese de lignina que fortalece a parede celular contra a ação de enzimas líticas produzidas em abundância por alguns patógenos (Silva et al., 2008). As PFO catalisam a hidroxilação de monofenóis formando orto-difenóis e também a oxidação de ortodifenóis formando orto-quinonas, as quais exibem natureza antimicrobiana superior aos compostos fenólicos que as precedem (Valero et al., 1988). Aumento ou decréscimo na atividade de enzimas relacionadas com a resposta de defesa das plantas a patógenos detectadas durante todo o curso do processo infeccioso é um fenômeno normal diante de todas as possíveis mudanças citológicas decorrentes da íntima interação patógeno-planta. As isoformas das enzimas podem variar tanto quantitativa quanto qualitativamente em função da espécie da planta, do tipo de tecido analisado, do estádio fenológico da planta e do ambiente.

O ASM foi eficiente em aumentar a atividade apenas das enzimas QUI e GLU. O ASM é reconhecidamente eficiente em induzir a resistência de várias espécies de plantas a patógenos (Guzzo et al., 2004; Lyon, 2007). Comparativamente ao $\mathrm{ASM}$, o $\mathrm{KSi}$, independente do $\mathrm{pH}$ 


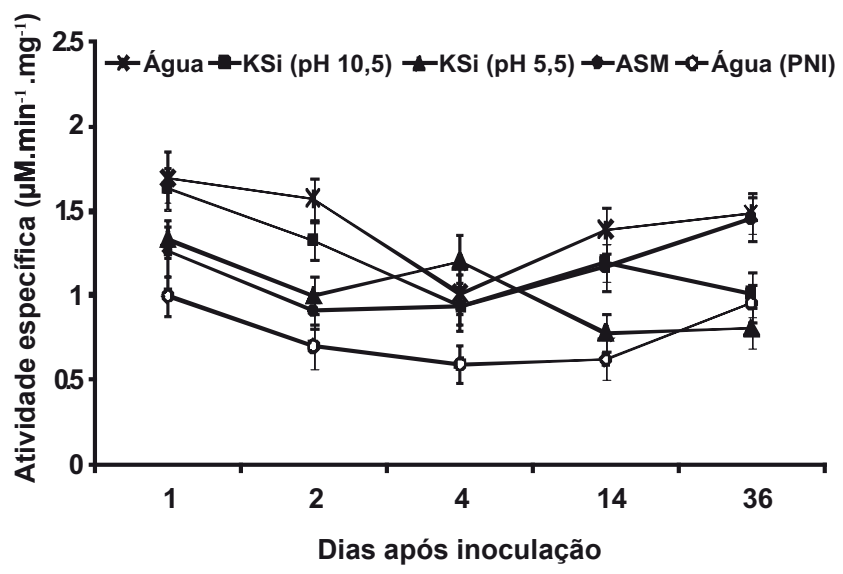

FIGURA 6 - Atividade específica de lipoxigenases em folhas de mudas de cafeeiro determinada em diferentes épocas após a inoculação com Hemileia vastatrix e que receberam previamente a aplicação foliar de água destilada silicato de potássio $(\mathrm{KSi})(\mathrm{pH}$ 10,5), KSi (pH 5,5) e acibenzolar-S-metil (ASM). Plantas não inoculadas (PNI) receberam aplicação de água destilada. Barras representam o desvio padrão da média.

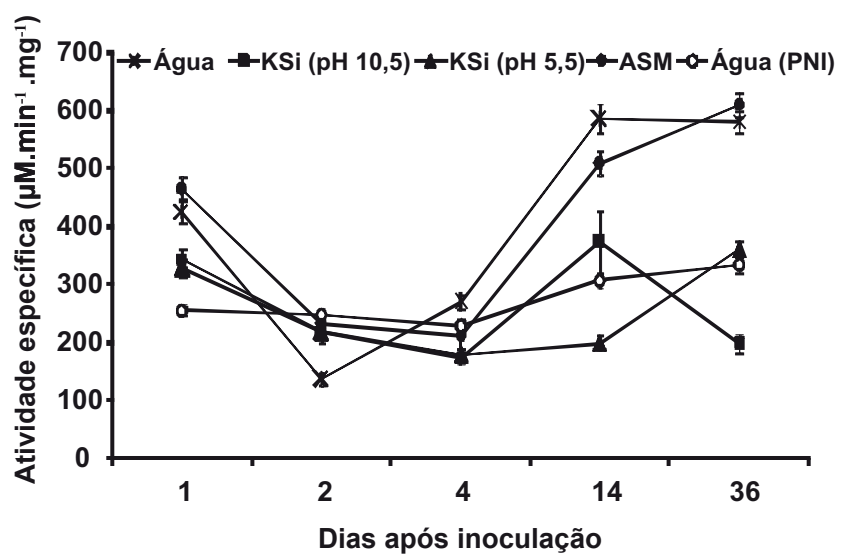

FIGURA 7 - Atividade específica de fenilalanina amônia-liases em folhas de mudas de cafeeiro determinada em diferentes épocas após a inoculação com Hemileia vastatrix e que receberam previamente a aplicação foliar de água destilada, silicato de potássio $(\mathrm{KSi})(\mathrm{pH}$ 10,5), KSi (pH 5,5) e acibenzolar-S-metil (ASM). Plantas não inoculadas (PNI) receberam aplicação de água destilada. Barras representam o desvio padrão da média.

da solução, foi ineficiente em potencializar a atividade das enzimas estudadas. O Si tem potencial em maximizar as respostas de defesa de plantas como o arroz, trigo e pepino a patógenos foliares através da produção de compostos fenólicos, aumento na produção de algumas classes de fitoalexinas, na transcrição de alguns genes que codificam as enzimas FAL, POX e PFO, além do aumento na atividade das enzimas líticas à parede celular fúngica GLU e QUI, ou associadas com o metabolismo secundário da planta (Datnoff et al., 2007; Liang et al., 2005). Isto ocorrerá desde que o Si seja passiva e ou ativamente absorvido pela planta atingindo um elevado teor nos seus tecidos. Acredita-se que o silicato polimerizado sobre a superfície das folhas de café passa a afetar de certa forma o processo infeccioso de $H$. vastatrix devido ao aumento no potencial osmótico ou formando placas de silicato, após polimerização, sobre os estômatos, local de entrada do patógeno, já que o teor foliar de Si não aumentou após a aplicação de KSi. De acordo com Liang et al. (2005), a aplicação foliar de Si, ao contrário do seu fornecimento via raiz, não contribuiu para aumentar a atividade das enzimas POX, PFO, FAL e QUI em plantas de pepino com sintomas de míldio pulverulento.

Os resultados desse trabalho indicam que a aplicação foliar de KSi, na tentativa de fornecer $\mathrm{Si}$ ao cafeeiro, embora tenha contribuído para reduzir a severidade da ferrugem, não potencializou a atividade das enzimas de defesa avaliadas, ao contrário da aplicação de um indutor, reconhecidamente capaz de induzí-las. Assim, outros mecanismos podem estar envolvidos na redução da severidade da ferrugem e deverão ser elucidados futuramente.

\section{AGRADECIMENTOS}

Ao Conselho Nacional de Desenvolvimento Científico e Tecnológico - CNPq e a Fundação de Amparo à Pesquisa do Estado de Minas Gerais - FAPEMIG pelos recursos financeiros. A Coordenação de Aperfeiçoamento de Pessoal de Nível Superior - CAPES pela bolsa de mestrado concedida a S.C. Pereira e ao CNPq pelas bolsas de produtividade em pesquisa dos professores F.Á. Rodrigues, M.G.A. Oliveira e L. Zambolim. A empresa PQ Silicas do Brasil Ltda pelo fornecimento do FertiSil ${ }^{\circledR}$. Os autores agradecem ao Prof. Gaspar H. Korndörfer (Universidade Federal de Uberlândia) pela realização das análises de silício no material vegetal.

\section{REFERÊNCIAS BIBLIOGRÁFICAS}

Axelrod B, Cheesbrough TM, Laasko S (1981) Lipoxygenases from soybeans. Methods in Enzymology 71:441-451.

Botelho DMS, Pozza EA, Pozza AAA, Carvalho JG, Botelho CE, Souza PE (2005) Intensidade da cercosporiose em mudas de cafeeiro em função de fontes e doses de silício. Fitopatologia Brasileira 30:582-588.

Cahill DM, McComb JA (1992) A comparison of changes in phenylalanine ammonia-lyase, lignin and phenolic synthesis in the roots of Eucalyptus calophylla (field resistant) and E. marginata (susceptible) when infected with Phytophthora cinnamomi. Physiological and Molecular Plant Pathology 40:315-332.

Chance B, Maehley AC (1955) Assay of catalases and peroxidases. Methods in Enzymology 2:764-775.

Datnoff LE, Rodrigues FA, Seebold KW (2007) Silicon and Plant Nutrition. In: Datnoff LE, Elmer WH, Huber DM (Eds.) Mineral nutrition and plant disease. Saint Paul MN. APS Press, pp. 233-246. 
Guzzo SD, Castro RM, Kida K, Martins EMF (2001) Ação protetora do acibenzolar-S-metil em plantas de cafeeiro contra ferrugem. Arquivos do Instituto Biológico 68:89-94.

Guzzo SD, Harakava R, Lucon CMM, Tsai SM (2004) Resistência sistêmica adquirida em cafeeiro contra Hemileia vastatrix e indução local e sistêmica de quitinases e $\beta$-1,3-glucanases por acibenzolar-S-metil. Summa Phytopathologica 30:376-381.

Harman GE, Hayes CK, Lorito M, Broadway RM, Pietro A, Peterbauer C, Tronsmo A (1993) Chitinolytic enzymes of Trichoderma harzianum: purification of chitobiosidase and endochitinase. Phytopathology 83:313-318.

Kar M, Mishra D (1976) Catalase, peroxidase, and polyphenoloxidase activities during rice leaf senescence. Plant Physiology 57:315-319.

Korndörfer GH, Pereira HS, Nolla A (2004) Análise de silício: solo, planta e fertilizante. Uberlândia MG. Universidade Federal de Uberlândia. Boletim Técnico.

Kushalappa AC (1978) Uma escala para estimar a intensidade foliar de ferrugem do cafeeiro. Fitopatologia Brasileira 3:119. (Resumo)

Lever M (1972) A new reaction for colorimetric determination of carbohydrates. Analytical Biochemistry 47:273-279.

Liang YC, Sun WC, Si J, Römheld V (2005) Effects of foliar and root applied silicon on the enhancement of induced resistance to powdery mildew in Cucumis sativus. Plant Pathology 54:678685.

Lyon G (2007) Agents that can elicit induced resistance. In: Walters D, Newton A, Lyon G (Eds.) Induced resistance for plant defense: a sustainable approach to crop protection. Oxford. Blackwell Publishing. pp. 9-29.

Ma JF, Yamaji N, Mitani N, Tamai K, Konishi S, Fujiwara T, Katsuhara M, Yano M (2007) An efflux transporter of silicon in rice. Nature 448:209-213.

Mitani N, Ma JF (2005) Uptake system of silicon in different plant species. Journal of Experimental Botany 56:1255-1261.

Okinaka Y, Mimori K, Takeo K, Kitamura S, Takeuchi Y, Yamaoka N, Yoshikawa M (1995) A structural model for the mechanisms of elicitor release from fungal cell walls by plant $\beta$ 1,3-endoglucanase. Plant Physiology 109:839-845.
Pozza AAA, Alves E, Pozza EA, Carvalho JG, Montanari M, Guimarães PTG, Santos DM (2004) Efeito do silício no controle da cercosporiose em três variedades de cafeeiro. Fitopatologia Brasileira 29:185-188.

Roberts WK, Selitrennikoff CP (1988) Plant and bacterial chitinases differ in antifungal activity. Journal of General Microbiology 134:169-176.

Rodrigues FA, Jurick WM, Datnoff LE, Jones JB, Rollins JA (2005) Silicon influences cytological and molecular events in compatible rice-Magnaporthe grisea interactions. Physiological and Molecular Plant Pathology 66:144-159.

Schuster B, Rétey J (1995) The mechanism of action of phenylalanine ammonia-lyase: the role of prosthetic dehydrolanine. Proceedings of the National Academy of Sciences USA 92:84338437.

Silva MC, Guerra-Guimarães L, Loureiro A, Nicole MR (2008) Involvement of peroxidases in the coffee resistance to orange rust (Hemileia vastatrix). Physiological and Molecular Plant Pathology 72:29-38.

Silva MD, Oliveira MGA, Lanna AC, Pires CV, Piovesan ND, Jose IC, Batista RB, Barros EG, Moreira MA (2001) Caracterização da via das lipoxigenases em plantas de soja resistentes e susceptíveis a Diaporthe phaseolorum f.sp. meridionalis, agente causal do cancro-da-haste. Revista Brasileira de Fisiologia Vegetal 13:316328.

Valero E, Varón R, Carmona GF (1988) Characterization of polyphenoloxidase from airen grape. Journal of Food Science 53:1482-1485.

Várzea VMP, Marques DV (2005) Population variability of Hemileia vastatrix vs. coffee durable resistance. In: Zambolim L (Ed.) Durable Resistance to Coffee Leaf Rust. Viçosa MG. Universidade Federal de Viçosa. pp. 53-74.

Zambolim L, Vale FXR, Costa H, Pereira AA, Chaves GM (2002) Epidemiologia e controle integrado da ferrugem do cafeeiro. In: Zambolim L (Ed.) O Estado da Arte de Tecnologias de Produção de Café. Viçosa MG. Universidade Federal de Viçosa. pp. 369450.

Zucker M (1965) Induction of phenylalanina deaminase by light and its relation to chlorogenic acid synthesis in potato tuber tissue. Plant Physiology 40:779-784. 